\title{
Superstars and Me: Predicting the Impact of Role Models on the Self
}

\author{
Penelope Lockwood and Ziva Kunda \\ University of Waterloo
}

\begin{abstract}
The authors propose that superstars are most likely to affect self-views when they are considered relevant. Relevant superstars provoke self-enhancement and inspiration when their success seems attainable but self-deflation when it seems unattainable. Participants' self-views were affected only when the star's domain of excellence was self-relevant. Relevant stars provoked self-enhancement and inspiration when their success seemed attainable in that participants either still had enough time to achieve comparable success or believed their own abilities could improve over time. Open-ended responses provided rich evidence of inspiration in these circumstances. Relevant stars provoked, if anything, self-deflation when their success seemed unattainable in that participants either had already missed the chance to achieve comparable success or viewed their abilities as fixed and so unlikely to improve.
\end{abstract}

It is a cultural cliché that superstars, that is, individuals of outstanding achievement, can serve as role models to others, inspiring and motivating them to do their utmost best. To promote such inspiration, prominent women scientists are often invited to address high school girls, eminent African Americans are introduced to African American children, and outstanding employees are profiled in corporate newsletters and bulletin boards. In the domain of public policy, affirmative action plans are often justified on the grounds that they will create role models who will inspire members of disadvantaged groups. In both the public and private sector, there are countless examples of programs showcasing the talents or successes of a superior individual that are designed to boost the aspirations and selfimages of a particular target group.

However, our culture also holds the opposite cliché, that superstars can demoralize and deflate less outstanding others. This notion was brilliantly captured in the movie Amadeus (Forman, 1984) in the image of Salieri, the accomplished musician whose self-view, indeed whose whole life, was shattered by exposure to Mozart's genius. More familiar everyday scripts include the image of the "superwoman" who makes other, less extraordinary women feel incompetent by comparison and the image of the perfectly competent child who is demoralized by a gifted

Penelope Lockwood and Ziva Kunda, Department of Psychology, University of Waterloo, Waterloo, Ontario, Canada.

This research was supported by a grant from the Social Sciences and Humanities Research Council of Canada (SSHRC) and from the Natural Sciences and Engineering Research Council of Canada and by an SSHRC doctoral fellowship. Partial reports of these data were presented at the May 1996 conference of the Midwestern Psychological Association in Chicago and at the August 1996 conference of the American Psychological Association in Toronto. We are grateful to Lisa Sinclair and Joanne Wood for comments on an earlier version of this article and to Mike Busseri for his assistance with data collection.

Correspondence concerning this article should be addressed to Ziva Kunda, Department of Psychology, University of Waterloo, Waterloo, Ontario, Canada N2L 3GI. Electronic mail may be sent via the Internet to zkunda@watarts.uwaterloo.ca. sibling to the point of giving up on school. This notion, that outstanding others can be demoralizing, also gained support from the now classic "Mr. Clean and Mr. Dirty" study (Morse \& Gergen, 1970), in which job applicants viewed themselves less positively when faced with a superior competitor than when faced with an inferior one.

It is assumed, then, that superstars can lead to self-enhancement and inspiration under some circumstances and to selfdeflation and demoralization under others. In still other circumstances, superstars are expected to have no effect at all on people's self-views-one may watch the superb performance of Olympic medalists without experiencing any change in selfevaluation or motivation. Several theorists have struggled with the question of what determines whether and how people's selfviews are affected by outstanding individuals (e.g., Brickman \& Bulman, 1977; Collins, 1996; Taylor \& Lobel, 1989; Tesser, 1991; Wood, 1989).

Despite these theoretical efforts, remarkably little research has examined the impact of outstanding others on people's selfperceptions (cf. Collins, 1996). Following Festinger's seminal (1954) article on social comparison, many studies have investigated the comparisons that people draw between themselves and others. However, most of this research has focused on identifying whom one will choose to compare oneself to under different circumstances (Wood, 1989). Much less attention has been given to the consequences of comparisons that are thrust on one. A notable exception is the Self-Evaluation-Maintenance (SEM) model, developed by Tesser and his colleagues (e.g., Tesser, 1991; Tesser \& Campbell, 1983), that examines the processes through which people maintain positive self-evaluations in the face of potentially threatening comparisons with others. However, in their research, Tesser and his colleagues have not actually assessed the impact of others on people's self-evaluations, focusing instead on uncovering evidence for cognitive and behavioral work aimed at maintaining and enhancing selfevaluations following social comparison. Their research did not address the question of what, if any, the remaining effects are on the self.

A small number of studies have examined the impact of up- 
ward comparisons, that is, comparisons to superior others, on self-evaluations. However, in most of these studies, participants were given only very impoverished information about the superior other in the form of a photograph revealing physical attractiveness (e.g., Brown, Novick, Lord, \& Richards, 1992; Cash, Cash, \& Butters, 1983) or a score on a single ability test (cf. Brewer \& Weber, 1994). It is not obvious that reactions to such limited information will resemble reactions to a more realistically multidimensional person who has achieved more substantial and meaningful success. In particular, a richer portrayal may be crucial to the adoption of an outstanding other as a role model capable of clarifying one's goals and guiding one's aspirations. A handful of studies have included more detailed portraits of a high-achieving other. However, these studies examined the difference between upward comparisons to such a superior other and downward comparisons to an inferior other. They lack a crucial no-comparison control group (Brewer \& Weber, 1994; Brickman \& Bulman, 1977; Gastorf \& Suls, 1978; Major, Sciacchitano, \& Crocker, 1993; Morse \& Gergen, 1970). It is therefore unclear from these studies whether differences in reactions to the superior and inferior individuals are due to the impact of the superior individual, the inferior individual, or both. An important line of work has investigated how people facing threats such as cancer or marital breakup are influenced by upward comparisons, that is, comparisons with others in sirnilar circumstances who are doing better than they are (Buunk, Collins, Taylor, Van Yperen, \& Dakof, 1990; Taylor \& Lobel, 1989). However, this research typically involves self-reports of the effects of past comparisons, and these can be heavily influenced by participants' theories.

Methodological problems aside, the relevant studies do not paint a clear picture of the impact of outstanding others on the self because they have yielded mixed results. In some, comparisons to superior others appear to be self-enhancing, in some they appear to be self-deflating, and in some they seem to have no effect on self-views (for a review, see Collins, 1996). In this article, we aim to identify the circumstances under which each of these outcomes will occur. We examine what determines whether people compare themselves to superstars and, when they do, what determines the outcome of such comparisonwhen will it lead to self-enhancement and inspiration and when will it lead to self-deflation and discouragement?

We propose that superstars are most likely to affect selfviews when they are considered relevant. The impact of relevant superstars depends on the perceived attainability of their success: Individuals will be enhanced and inspired by a superstar if they believe that they too can attain comparable success but will be demoralized and deflated if they believe that they cannot. Our thinking on these issues has been greatly influenced by the theoretical analysis of Major, Testa, and Bylsma (1991). These authors developed a similar model and also pointed to the lack of direct evidence for it. We turn next to a more detailed discussion of the two factors that we consider crucial in determining the impact of a superstar on others: the perceived relevance of the superstar to the self and the believed attainability of the star's success.

\section{Relevance}

A superstar will become a source of inspiration or discouragement only if one compares oneself to this person. One is most likely to draw such comparisons berween oneself and an outstanding other when the other is viewed as relevant to the self (cf. Major et al., 1991). What determines relevance? Our answer is informed by research on analogy, because social comparison may be viewed as drawing an analogy between the self and the other or, in other words, mapping the self onto the other (Thagard \& Kunda, in press). People are most likely to draw analogies between two objects when the two resemble each other in features, structure, and purpose (Holyoak \& Thagard, 1995; Markman \& Gentner, 1993). These similarities are integrated and jointly affect the likelihood that one object, or, in the case of social comparison, one person, will be mapped onto the other (Holyoak \& Thagard, 1989).

Research on social comparison confirms that similarity between self and other increases the likelihood of social comparison. People are particularly likely to seek comparisons with others who are similar to them in various ways (Goethals \& Darley, 1977; Wood, 1989). When one is outperformed by another, one is especially likely to engage in defensive thoughts and actions if the other is similar to the self on dimensions such as age, race, gender, or personality (Tesser, 1986; Tesser \& Campbell, 1983). Highly attractive others influence perceptions of one's own attractiveness only if they are of the same sex (Brown et al., 1992). Also, comparisons with another who has performed better or worse than oneself are undermined on reflection when the other is known to have acted under circumstances that differ from one's own (Gilbert, Giesler, \& Morris, 1995). All this suggests that as one's similarity in features or circumstances to an outstanding other decreases, the other is deemed less relevant for the purpose of social comparison and is therefore less likely to affect one's self-view.

The self-relevance of the superstar's domain of excellence can also contribute to the likelihood that one will compare oneself to the superstar (cf. Brewer \& Gardner, 1996; Major et al., 1993; Salovey \& Rodin, 1984) inasmuch as it increases the correspondence between oneself and the star. The self-views of university professors seem more likely to be affected by academic superstars than by athletic ones, because an academic star can be more readily mapped onto a professor's self. Domain self-relevance is not an essential requirement for social comparison - if there are enough other similarities between the self and the superstar, the superstar may affect one's self-view even if he or she excels in an irrelevant domain (Tesser, 1986; Tesser \& Campbell, 1983). This seems particularly likely if the superstar is a sibling or a close friend, because there are typically so many similarities in attributes and circumstances among siblings and friends that comparisons are all but inevitable. However, all other things being equal, domain self-relevance may determine whether or not one engages in comparison with more distant superstars in the first place.

Our view of the role that domain relevance plays in upward comparisons differs from that outlined in Tesser's SEM model (Tesser, 1988; Tesser \& Campbell, 1983). In the SEM model, whether an outstanding other will have any impact on the self depends on the extent to which the other is psychologically close. Psychological closeness is assumed to increase with attribute similarity, physical proximity, family ties, similarity in place of origin, and so on. Tesser and his colleagues conceptualized domain self-relevance as a separate factor that determines only 
the direction of the target's impact on the self. In Tesser's model, the star is expected to have a negative impact when relevant (and therefore threatening) but a positive impact when irrelevant. In that model, relevance plays no role in determining whether the star will exert any impact on the self in the first place. In contrast, in our view, domain self-relevance, like psychological closeness, can serve to increase the correspondence between the self and the star. When a superstar excels at one's own domain of interest, this increases the similarity between oneself and the superstar and, thereby, the likelihood that one will draw an analogy between oneself and the star. Our studies focus on this role of relevance, which has thus far received little research attention. We assume that relevance and closeness can increase the likelihood of social comparison in a similar manner, but we do not examine whether these dimensions constitute a single construct or two orthogonal ones.

\section{Attainability}

When an outstanding individual seems relevant, one will compare oneself to this individual. The consequences of this comparison for the self will then depend on the perceived attainability of that individual's success. If the superstar's success seems attainable, one will be inspired. The superstar illustrates the wonderful heights of accomplishment one can hope to achieve, encourages and motivates one to strive for this now all the more palpable success, indicates particular goals to aim for along the way, points to the road one should follow to achieve them, and makes one feel more competent and capable of such achievement. On the other hand, if the superstar's success seems unattainable, one will be discouraged and demoralized. The superstar's success highlights one's own failures and shortcomings. One realizes that one can no longer hope for comparable stardom, one's own lesser achievement seems paltry by comparison, and one feels disheartened and inferior (cf. Major et al., 1991).

The notion of personal inspiration outlined above lies at the heart of the popular understanding of role models and their presumed positive impact. Yet this notion has received little attention in social psychological research. Researchers investigating cancer patients have noted that these patients gain hope and inspiration from better off cancer patients who can serve as a source of information on coping and survival (Taylor \& Lobel, 1989). Reviewers of social comparison research have also noted that superior others can sometimes serve as inspirational role models (e.g., Collins, 1996; Wood, 1989). However, for the most part, these insights have not been incorporated into prevailing theories of how people are influenced by others who are superior to them in ability and achievement (e.g., Brewer \& Weber, 1994; Tesser, 1991).

To be sure, several theorists have suggested that superior others can have positive consequences for the self; however, these benefits are typically conceptualized as resulting from a process that is quite different in nature from inspiration. Tesser's reflection process (1988) and Cialdini's basking in reflected glory (Cialdini et al., 1976) both describe mechanisms by which an individual is positively affected by the triumphs of a close other. However, such positive impact stems not from the opening up of possibilities for the self but, rather, from the pride of association with the other. One feels good about oneself not because "I can achieve wonderful heights" but because "I belong to a wonderful group." Indeed, such basking in the reflected glory of others has been shown to occur only when one's own central self-conceptions are not engaged: It occurs only when the other excels at a domain that is irrelevant to the self (Tesser, 1988); it occurs only when one holds one's own personal self at bay, highlighting instead one's social self (Brewer \& Weber, 1994); and it occurs when one has no need to dwell on one's self-view because one is confident about it (Pelham \& Wachsmuth, 1995). When these conditions are not met, the superior other is expected to have a negative rather than positive impact on the self. The implication is that when one's personal identity is salient, as is typically the case for North Americans (Markus \& Kitayama, 1991), someone who is outstanding in a domain that one cares deeply about-the very definition of a role model-can only demoralize, never inspire one.

This emphasis on the negative consequences of comparisons to others who are superior on self-relevant dimensions is rooted in the original view of social comparison as providing a means of assessing one's current abilities (Festinger, 1954). Current abilities are inevitably inferior to those of a superior other, and if one were to focus only on that inferiority, demoralization would undoubtedly ensue. However, a different picture emerges if one recognizes that people's self-views incorporate more than their current abilities; possible future selves also play a central role in guiding aspirations and satisfaction and may sometimes be even more important to well-being than are current selfconceptions (Markus \& Nurius, 1986). The realization that one is currently less successful than another may lose its sting if it is accompanied by the belief that one will attain comparable success in the future. Role models can enhance and inspire by making successful future selves appear more tangible and by illustrating how future achievements may be accomplished (Meichenbaum, 1971).

In focusing on such personal inspiration, we do not mean to challenge the reality or importance of the reflection process highlighted by other theorists, for which there is ample evidence (Brewer \& Weber, 1994; Cialdini et al., 1976; Tesser, 1988). We do, however, wish to point out that outstanding others can also lead to a different kind of positive consequence - inspiration-that could arise under circumstances in which basking in reflected glory is unlikely. Moreover, we question a central supposition of Tesser's SEM model (Tesser, 1988; Tesser \& Campbell, 1983), namely, that close others who excel at a selfrelevant domain will invariably have negative consequences for the self. We believe that such negative consequences will occur only when the other's success seems unattainable. When it seems attainable, the consequences for the self will be positive.

Tesser and his colleagues may have overlooked the possibility that others who are superior on a self-relevant dimension can exert a positive impact on the self because, in their experiments, the other's elevated performance was typically unattainable and the other's superiority to the self irrevocable-precisely the conditions under which we too expect a negative impact on the self. In relevant SEM experiments, the other's superiority was established by informing participants that the other had outperformed them on a novel test that both had just taken. Participants were confronted either with a single score on a test that they 
did not expect to take again (Pleban \& Tesser, 1981; Tesser \& Cornell, 1991; Tesser \& Paulhus, 1983) or with scores on several items given in rapid succession with no opportunity to practice and improve from one item to another (Tesser, Millar, \& Moore, 1988). In such circumstances there can be no hope of improving one's standing relative to the other in the future; the other's superior level of success is unattainable and, therefore, threatening and demoralizing (cf. Major et al,, 1991). This research leaves open the possibility that others who excel on a selfrelevant domain can be inspiring when their excellence seems attainable.

There is some support for the prediction that relevant superstars lead to inspiration when their success seems attainable but to demoralization when it seems unattainable. Major et al.'s review (1991) concluded that the impact of a superior other was positive in studies in which participants most likely viewed their own performance as controllable (and so viewed future success as attainable; e.g., Meichenbaum, 1971; Seta, 1982), but the impact of superior others was negative in studies in which participants most likely viewed future success as unattainable (e.g., Salovey \& Rodin, 1984; Tesser \& Paulhus, 1983). However, the conclusion that the perceived attainability of success determines the impact of a superstar remains speculative because it is based mostly on post hoc comparison of studies that provided examples of attainable success to other studies that provided examples of unattainable success. One study that did vary the attainability of future success found that receiving lower test scores than others led to more negative consequence when participants believed their own performance could improve than when they believed it could not (Testa \& Major, 1990). However, this study did not include a no-comparison baseline, so the absolute impact of comparisons in both these conditions remains unknown. Wood and VanderZee (in press), reviewing research on cancer patients' comparisons to better off others, concluded that such comparisons are pleasing and inspiring when similar outcomes seem attainable but demoralizing when they do not. However, that research involved patients' descriptions of their typical reactions to such comparisons rather than more rigorous experimental designs. Moreover, it is unclear whether the dynamics of upward comparisons in the domains of ability and achievement are the same as in the domains of health and survival. Thus, although there is reason to believe that the impact of superstars depends on the perceived attainability of their success, there is no direct and conclusive evidence for this hypothesis. We aimed to test it more directly.

In this article, we examine the impact of superstars on people's self-perceptions. In all our studies, we provided participants with detailed, richly portrayed descriptions of a person of outstanding accomplishment. We expected that the impact of such a superstar on the self would be greater when the superstar's domain of excellence was relevant to the self. Study 1 examined this hypothesis. We further expected that the direction of this impact would depend on the perceived attainability of the superstar's success. When a star's accomplishments appear attainable, people will be inspired and their self-views will be enhanced. In contrast, when the star's achievements seem out of reach, people will be threatened, and their self-views will be deflated. Studies 2 and 3 examined this hypothesis. We also attempted to document inspiration by analyzing participants' open-ended responses.

\section{Study 1. Relevance: An Outstanding Teacher or Accountant Has Different Consequences for Future Teachers and Accountants}

We hypothesized that superstars can be inspiring if they excel at a relevant domain and their success seems attainable. In our first study, we attempted to create a star whose success would seem attainable and focused on examining whether the star's impact would depend on the star's relevance. We expected that superstars would give rise to greater inspiration and self-enhancement when they were perceived as more self-relevant.

We manipulated the self-relevance of a superstar's domain of excellence by exposing students to someone who had cxcelled at their own intended profession or at a different profession. Wc focused on the professions of teaching and accounting because these were the most common intended professions in the available pool of participants. In addition, they seem sufficiently different from each other that a future teacher might consider an outstanding accountant to be completely irrelevant. We identified participants who planned to become teachers or accountants and exposed them to a description of either an outstanding teacher or an outstanding accountant. We reasoned that because the star had excelled at tasks that participants' themselves had not yet undertaken, participants would likely view similar levels of success to be within their own reach and so would be inspired by the star. We expected that participants would be more inspired by a superstar who excelled at their own intended profession than by one who excelled at a different profession.

\section{Method}

Participants. Participants were 50 female University of Waterloo undergraduates enrolled in Introductory Psychology who participated for course credit. At the beginning of the term, participants filled out a lengthy prescreening measure that included a questionnaire assessing career plans. The two most common future professions were teaching and accounting. We therefore focused on these and randomly selected participants from the lists of future teachers and future accountants. Because most of the future teachers were women, we included only women in the study. Altogether, 32 future teachers and 18 future accountants took part in the study.

Procedure. Three to ten weeks after completing the prescreening measure, participants were recruited for a study on the effects of journalistic styles on social perception. Experimental participants read a bogus newspaper article describing either a teacher or an accountant who had recently won an award for her outstanding career achievements; both targets were women. The high-achieving teacher was portrayed as having been highly successful in motivating her students at an inner city high school, meeting difficult challenges with enthusiasm. She was described by her school principal as "one of the most talented, creative, and innovative teachers" he had ever worked with. The high-achieving accountant was portrayed as having shown remarkable progress in her career, becoming one of the youngest employees ever to receive a partnership at her well-respected accounting firm. She was described by her supervisor as "one of the most extraordinarily talented and innovative individuals" that he had ever worked with.

Dependent measures. After reading the article, experimental participants read that before being asked about the article they would be asked 
some questions about themselves to determine whether their personality had any impact on their perceptions of the article. They then rated themselves on 40 adjectives among which were embedded 10 that related positively to general career success (e.g., bright, skillful) and 10 that related negatively to such success (e.g., incompetent, unintelligent). ${ }^{1}$ All items were rated on an 11-point scale with endpoints labeled 1 (not at all) and 11 (very). Participants then rated the target on the same items.

Next, participants rated how relevant the target was to them for the purpose of comparison on an 11-point scale with endpoints labeled 1 (completely irrelevant) and 11 (very relevant). They then wrote an explanation of why they had answered this question as they had.

We also included a control group of future teachers who provided self-ratings without first reading about a target. We were unable to include a control group of future accountants because there were not enough of them in the available pool of participants. Control group participants read the same cover story but were asked to provide the self-ratings before they read the article.

In sum, the design was 2 (participants' future profession: teaching or accounting) $\times 2$ (target's profession: teacher or accountant) with an additional no-target control group for future teachers. Participants in each future profession group were randomly assigned to conditions.

\section{Results and Discussion}

Ratings of target. We averaged success-related items into a single index of the target's success after first reversing the negative items (Cronbach's $\alpha=.79$ ). A 2 (Participants' future profession ) $\times 2$ (Target's profession) analysis of variance $(A N-$ OVA ) revealed that the accountant $(M=10.09)$ was rated higher than the teacher $(M=9.56), F(1,36)=5.24, p<.05$. This effect poses no problems for the interpretation of participants' self-ratings because even the teacher was rated very highly, and, as we show below, the two targets provoked comparable effects. The high target ratings indicate that we were successful in portraying individuals of outstanding achievement. The main effect of participants' future profession and the interaction were not significant (both $p s>.20$ ).

Self-ratings. We recoded the variable reflecting the target's profession in terms of the target's relevance to participants. The target was coded as relevant when her profession was the same as participants' intended profession (i.e., the teacher was relevant to future teachers and the accountant to future accountants ) and was coded as irrelevant when her profession differed from participants' intended profession (i.e., the teacher was irrelevant to future accountants and the accountant to future teachers). We used a 2 (participants' future profession) $\times 2$ (relevance of target's occupation) factorial design with an additional nonorthogonal control group for future teachers. We first analyzed the data from the factorial design by using a $2 \times 2$ ANOVA. Next, we performed a one-way ANOVA on ratings made by future teachers with 3 levels of target (teacher, accountant, and control). This provided the error term used in planned comparisons among these conditions.

Self-ratings were averaged into an index of success as target ratings had been (Cronbach's $\alpha=.89$ ). As can be seen in Table 1 , both future teachers and future accountants who were exposed to a superstar evaluated themselves more positively when the superstar was relevant to them than when the superstar was irrelevant. This main effect was significant, $F(1,36)=5.39$,
Table 1

Mean Self-Evaluations of Future Accountants and Future Teachers Exposed to a Relevant Target (Who Excelled at Their Own Intended Profession), an Irrelevant Target (Who Excelled at the Other Profession), or No Target

\begin{tabular}{lccc} 
& \multicolumn{3}{c}{ Target type } \\
\cline { 2 - 4 } Future occupation & Relevant & Irrelevant & No target \\
\hline Future accountants & 8.24 & 7.68 & - \\
Future teachers & 8.64 & 7.66 & 7.67 \\
\hline
\end{tabular}

Note. Higher numbers indicate more positive self-evaluations.

$p<.05$. The main effect for participants' future occupation and the interaction did not approach significance (both $F_{\mathrm{S}}<1$ ).

Examination of the control group included for future teachers suggests that the obtained differences in self-ratings following exposure to the relevant and irrelevant role models were due entirely to the self-enhancing impact of the relevant one; the irrelevant role model had no impact on self-ratings. The selfevaluations of future teachers exposed to the irrelevant accountant role model were almost identical to those of controls, as can be seen in Table 1. However, future teachers exposed to the relevant teacher role model rated themselves more positively than did controls or those exposed to the irrelevant role model. This difference was significant, as revealed by a planned contrast comparing future teachers exposed to the relevant target to the average of the irrelevant-target and control conditions, $F(1,29)=5.70, p<.05$. It appears, then, that the relevant role model had a positive influence on participants, but the irrelevant role model had no impact.

Ratings of target's relevance. As expected, participants rated the target who was outstanding in their own future profession as more relevant to them than the other target, $F(1,36)=$ $13.32, p<.001$. The main effect for participants' future occupation and the interaction did not approach significance (both $F_{\mathrm{s}}<1$ ). Thus we had successfully manipulated the perceived relevance of the targets to participants.

Moreover, the differential impact of the two targets on the two groups of participants appears to have been due to these differences in the targets' perceived relevance. To test whether the target's perceived relevance mediated the impact of the target's future profession on self-ratings, we conducted a series of regression analyses ( Baron \& Kenny, 1986). First, we regressed relevance ratings on target's occupation (which was coded as relevant or irrelevant to participants as in the previous analysis ) and obtained a significant effect $(\beta=.52, p<.001)$. Second, we regressed self-ratings on target's occupation and obtained a significant effect $(\beta=.37, p<.02)$. Third, we regressed self-ratings on both target's occupation and relevance ratings. Relevance ratings had a significant effect on self-ratings $(\beta=$ $.40, p=.02$ ). The effects of target's occupation on self-ratings were substantially lower in the third than in the second regression equation and were no longer significant $(\beta=.16, p>$

\footnotetext{
${ }^{1}$ One of these (inept) was removed from the index because several participants expressed uncertainty about its meaning.
} 
.25 ). Thus, controlling for the effects of relevance ratings climinated the effects of target's occupation on self-ratings.

Explanations. We have suggested that the relevant superstars had a positive impact on participants because participants were inspired by these individuals. We examined participants' open-ended explanations of their ratings of the target's relevance for evidence of such inspiration. We expected that participants would articulate that they were inspired by the role model and that they would be more likely to do so when the role model was relevant to them.

Two raters unaware of the study's hypotheses coded participants' responses. Raters were also initially unaware of participants' condition, although participants' responses often revealed the target's profession and their own intended one. Participants were considered to show inspiration if they indicated that they had found the target motivating or inspiring (e.g., "This type of dedication and success in the teaching field is quite inspirational. It is amazing and motivating to see how just one teacher can affect so many individuals." ), if they said the target had motivated them to work harder (e.g., "If I judge myself by her standards I will work harder to achieve my goals, so that I can have what she has [only better]."), if they indicated that exposure to the target had given them new or enhanced goals (e.g., "Moving up the ranks so quickly is something I can try to aim for figuring that an example has already been set."), if they said that they wanted to become like the target (e.g.; "I want to see my name where hers is today."), or if they explicitly referred to the target as a role model. The raters agreed on $85 \%$ of the cases; discrepancies were resolved through discussion.

The relevant role model was considerably more likely than the irrelevant one to provoke inspiration. Of the participants exposed to the relevant role model, $45 \%$ indicated that the target had inspired them, whereas only $15 \%$ of participants exposed to the irrelevant target indicated any inspiration $(z=2.07, p$ $<.05)$. Thus, the subjective experience of inspiration by an outstanding other is quite common and is particularly likely to be induced by relevant superstars.

\section{Study 2. Attainability: An Outstanding Graduating Student Has Different Consequences for First- and Fourth-Year Students}

Study 1 suggested that a star's perceived relevance can determine whether the star will have any impact on others. In Study 1, this impact was positive: The relevant star induced self-enhancement and inspiration. Other studies, however, have suggested that relevant stars can also exert a negative impact (Tesser, 1991 ). Study 2 examined what determines the direction of the impact exerted by relevant superstars. We predicted that this impact would be positive when the achievements of the star seemed attainable but negative when they seemed unattainable. As noted earlier, this prediction is consistent with prior research, although there is no direct evidence for it (Major et al., 1991). It is also consistent with our everyday experience.

We have noticed that when an academic department is searching for a new professor, graduating doctoral students are often demoralized and deflated by job candidates whose credentials are superior to their own. But these same students seem inspired by outstanding visiting professors, even though these are typi- cally far more accomplished than the job candidates that the students find so threatening. We believe that young job candidates are so much more threatening to graduate students because they are at the same stage in their careers. The students must realize that it is already too late for them to accomplish in graduate school what these stars have managed to achieve. The outstanding job candidate therefore seems far more competent than they are. Such invidious comparisons can lead to discouragement and self-deflation. In contrast, visiting professors are older and more advanced in their careers. As such, they illustrate possible future accomplishments that students can still hope and strive to obtain. Students may believe that if only they work hard enough from now on, they too can be as successful 10 years down the road. Such a model of seemingly attainable excellence can inspire students and lead them to view their own abilities and prospects more brightly.

This analysis suggests that the relevant star in Study 1 was inspiring because she was at a more advanced career stage than the participants. Participants had not yet undertaken the tasks that she had excelled at and could therefore still believe that they too could attain such excellence. A study by Brickman and Bulman (1977, Experiment 3) yielded results consistent with these ideas: Participants viewed themselves more negatively after exposure to an outstanding peer than after exposure to an outstanding older person. However, because that study had no control group, the absolute impact of either target remains unknown.

To examine these ideas, we presented participants with a superstar whose success would seem attainable or unattainable by virtue of each participant's own career stage. To this end, we created a description of a spectacular graduating student who had majored in accounting and presented this description to entering and graduating accounting students. We chose this major because accounting is a highly selective program at the University of Waterloo, drawing students who excelled in high school. We reasoned that the achievements of the graduating superstar would seem attainable to first-year accounting students whose university careers still lay ahead and for whom any level of accomplishment still seemed within reach given their history of academic excellence. Therefore these students should be inspired and self-enhanced by the star. In contrast, we expected that the achievements of the same superstar would seem unattainable to fourth-year accounting students, for whom it was already too late to achieve a similar level of success at university; they had already established a less stellar record and had no time left to improve upon it. Therefore these students should be discouraged and self-deflated by the star.

\section{Method}

Parlicipants. Participants were 69 students of both genders enrolled in the School of Accountancy at the University of Waterloo. Students from first- and fourth-year accounting classes were recruited to participate, for pay, in a study on the effects of journalistic style on social perception. Four participants were excluded from the analyses, 2 because they did not list accounting as their intended occupation and 2 because their self-evaluation scores were more than three standard deviations from the mean, leaving a total of 65 participants. Participants' gender had no effects on any of the variables and therefore is not discussed further. 
Procedure. Participants were randomly assigned to the experimental or control group. Experimental participants read a bogus newspaper article, ostensibly from a local campus newspaper, describing a stellar fourth-year accounting student. The target was said to have recently won an important award for outstanding academic achievement. This student had a "superb academic record" and was praised by the Chair of the Accounting program as "innovative and creative." Moreover, because we did not want participants to dismiss the target as a "geek," the article also described the target's involvement in student government groups, volunteer activities, and various sports teams. This graduating student was a bright, well-rounded high achiever who had "demonstrated a high level of leadership and community involvement." The article was the same for all participants, with the exception that women read about a female target (Jennifer Walker) and men read about a male target (Jeffrey Walker).

After reading the article, experimental participants rated first the target and then themselves on a set of 10 positive and 10 negative traits relevant to general career success. Ratings were made on an 11-point scale with endpoints labeled 1 (not at all) and 11 (very).

Next, experimental participants were asked to list their intended occupation. This enabled us to confirm that they were planning to become accountants and therefore likely to view the target as relevant. Participants then rated the extent to which the target was relevant to them for the purpose of comparison on an 11-point scale with endpoints ranging from 1 (completely irrelevant) to 11 (very relevant) and were also asked to write down explanations for their responses to this question.

Participants in the control group completed the self-ratings without first reading about the target. After completing the questionnaire, participants were probed for suspicion and debriefed.

\section{Results and Discussion}

Ratings of target. Success-related items were averaged into a single index of the target's success after first reversing the negative items (Cronbach's $\alpha=.83$ ). Unexpectedly, fourthyear students $(M=9.72)$ rated the target somewhat less positively than did first-year students $(M=10.20), F(1,31)=$ $4.30, p=.05$. We suspect that this was due to a defensive reaction on the part of the fourth-year students; recognizing the target's achievements to be unattainable, they were perhaps attempting to cut the target down to size and thus minimize the negative impact on themselves (Tesser, 1988; Tesser \& Campbell, 1983). As we show below, we have other evidence for defensiveness on the part of fourth-year students. Note that, if anything, this pattern acts against our hypothesis. A less extremely successful target should be less, not more, threatening. But we predicted that fourth-year students, who viewed this target as somewhat less extremely successful, would be far more threatened by the target than would first-year students, because only fourth-year students would view the target's accomplishments as unattainable. Note also that even fourth-year participants rated the target very highly, suggesting that we were successful in portraying an outstanding individual.

Self-ratings. Unlike in Study 1, the correlation between the positive and negative items on the self-evaluation scales was low $(r=-.31) .^{2}$ Accordingly, we report the self-evaluation scores separately for the positive and negative items. The 10 positive items were averaged to form an index of positive selfevaluations (Cronbach's $\alpha=.86$ ), and the 10 negative items were averaged to form an index of negative self-evaluations (Cronbach's $\alpha=.84$ ).

Analyses of the positive self-evaluation index revealed that,
Table 2

Mean Self-Evaluations of First-and Fourth-Year Students Who Were and Who Were Not Exposed to an Outstanding Graduating Student

\begin{tabular}{ccc}
\hline & \multicolumn{2}{c}{ Target type } \\
\cline { 2 - 3 } Year in school & No target & Superstar \\
\hline First & 8.19 & 8.90 \\
Fourth & 8.29 & 7.88 \\
\hline
\end{tabular}

Note. Higher numbers indicate more positive self-evaluations.

as expected, the same outstanding graduating student exerted a different impact on first- and fourth-year students, as indicated by a significant interaction, $F(1,61)=4.98, p<.05$. As seen in Table 2, first-year students, for whom the target's achievements seemed attainable, were clearly enhanced by the target: Firstyear students exposed to the target rated themselves more positively than did first-year controls, $F(1,61)=4.37, p<.05$. In contrast, fourth-year students, for whom the target's accomplishments were unattainable, were, if anything, deflated by the target. Fourth-year students exposed to the target rated themselves less positively than did fourth-year controls, although this difference did not reach significance, $F(1,61)=1.23, p=.27$.

The target's impact on participants' self-views was restricted to the positive items. An analysis of the negative item index revealed no significant effects $\left(F_{\mathrm{S}}<1\right)$. This may reflect a floor effect. Negative self-ratings may have been too low among these highly accomplished participants to permit any further lowering even when their self-views were enhanced.

Ratings of target's relevance. Participants' ratings of the target's relevance to them as a comparison other revealed that fourth-year students actually rated the target as less relevant to them ( $M=6.81)$ than did the first-year students $(M=9.65)$, $F(1,31)=11.02, p<.01$. This pattern may seem surprising in that an objective observer might assume the opposite: students in the same class as the star (the fourth-year students) should view the star as more relevant than students in a different class (the first-year students). The obtained pattern is, however, consistent with research showing that people attempt to reduce their closeness to an outstanding other who threatens them (Pleban \& Tesser, 1981; Tesser, 1986). The superstar was more threatening to the fourth-year students because only they viewed the star's accomplishments as unattainable.

As in Study 1, participants' relevance ratings were positively associated with their self-ratings $(r=.19)$, but in this study, this effect was not significant $(p>.25)$. Most likely, results in this study were weaker because it had a more restricled range of relevance ratings: In this study, we created the targets to be highly relevant to all participants, whereas in Study 1 we intentionally varied the target's relevance.

Explanations. Participants' open-ended explanations of their relevance ratings shed further light on their responses. Two judges unaware of the study's hypotheses and of participants'

\footnotetext{
${ }^{2}$ The corresponding correlation in Study 1 was considerably stronger $(-.55)$.
} 
year in school coded these data for three types of responses: inspiration, denigration of the social comparison process, and similarity to the target. Agreement between the two coders was 94\% for the inspiration category, $97 \%$ for the comparison denigration category, and $85 \%$ for the similarity category. Discrepancies were resolved through discussion.

The criteria for classifying a response as showing inspiration were the same as in Study 1. We found dramatic differences on this measure between first- and fourth-year students. Whereas a large majority of first-year students described themselves as inspired ( $82 \%$ ), only a small minority of fourth-year students gave any indication of inspiration $(6 \%)$. This difference in proportions was significant $(z=4.41, p<.001)$.

We have suggested that a superstar can inspire by helping one set up clearer goals to shoot for and by motivating one to work harder toward these goals. First-year students provided vivid accounts of such inspiration. As one of them commented,

It is almost spooky how much alike Walker and I are: Firstly, I am in Arts Accounting Co-op and am an overachiever just like she is. Therefore because we are both female, planning on becoming Accountants I almost now want to work super-hard so that I can get that award that she got. . . I just decided that I will go to the ASA [Accounting Students' Association] meeting tomorrow now because it is probably a good idea to get involved like Jennifer did.

This student clearly believed the achievements of the role model to be within her own grasp, had incorporated the award as a new goal to strive for, had learned how to go about obtaining it, and was determined to work harder to achieve it.

Several of the first-year students indicated that the role model helped them delineate their achievement goals more clearly. As another first-year student noted,

Jeffrey Walker is very relevant to me for the purpose of comparison because what he has done is what my goals are. My goal is to become a CA and more important, I want to be at the top of my class. I also want to be well-rounded and have a life outside academics. Jeffrey Walker has done this through his athletics and volunteer work, and I would like to do the same. After seeing what Jeffrey has accomplished, I know what I must strive for.

For this student, the role model's accomplishments have provided a template to guide his own aspirations. Thus, a role model whose achievernents seem attainable can help individuals develop their goals in more practical, task-oriented ways.

As is clear from these representative responses, first-year students actively compared themselves to the superstar and were inspired by him or her. Fourth-year students, who provided little evidence of inspiration, reacted quite differently to the superstar. Analysis of the second class of responses that we coded for, denigrating the comparison process, shed light on their reactions. Participants were considered to have denigrated the comparison process if they stated that comparisons to another individual are pointless, that they preferred to judge themselves by their own standards rather than by referring to the achievements of others, or that they had too little information about the target to make a reasonable comparison. Below are representative examples of denigration of the comparison process, all voiced by fourth-year students:
I try to improve myself, but using who I was yesterday as a model for that comparison. Jeffrey is unknown to me . . . I have a set of special circumstances unique only to me and so does everyone else. To think otherwise is absurd. You can't compare 'success' between any 2 people on the planet because we are all different and successful in our own right.

$\mathrm{He}$ is in the same program and has the same career plans. However, I do not know enough of his personal character for him to be relevant.

JW is like a classmate to me. I'm usually influenced more by how I view myself than by how well I'm compared to my classmates. I'm more influenced by my own standards.

Such denigration of the comparison process was substantially more likely for fourth-year students $(50 \%)$ than for first-year students $(6 \% ; z=2.80, p<.01)$.

The third class of responses we coded for, similarity to the target, shed further light on participants' reactions to the target. For this measure, we counted only mentions of similarity on dimensions other than intended occupation (e.g., "She seems very similar to me. She aims to do well in school, like myself. She also participates in activities other than academic related like myself. Similarly, I like to help those in need," " [ She has the] same interests in sports, and the other involvements are similar to those I would be interested in.'). First-year students were considerably more likely to note such similarities between themselves and the target ( $53 \%$ ) than were fourth-year students $(19 \% ; z=2.05, p<.05)$. This difference may reflect motivated reactions on the part of both groups: First-year students may have exaggerated their similarity to the star so as to justify mapping themselves onto this outstanding person and inferring comparable future success for themselves, whereas fourth-year students may have played down any similarities between themselves and the star to justify viewing the star as irrelevant to them and as therefore nonthreatening.

In sum, it is apparent that first- and fourth-year students provided strikingly different accounts of their reactions to the target. Whereas first-year students focused on highlighting their similarity to the target and spelling out what they could learn from this outstanding person, fourth-year students concentrated on explaining why they could learn nothing about themselves from the target. Tesser and his colleagues (Tesser, 1986; Tesser \& Campbell, 1983) have proposed that when one is threatened by a superior other, one may attempt to dispel the threat by reducing closeness to the other, minimizing the other's performance, or reducing the relevance of the other's domain of achievement to the self. We too found evidence for some of these processes. The lower target ratings given by fourth-year students may reflect an attempt to minimize the target's performance. Their lower relevance ratings and mentions of similarity may reflect, in part, an attempt to reduce closeness. In addition, fourth-year participants' explanations point to yet another mechanism that people can rely on to diffuse the threat of an upward comparison: They may attempt to denigrate the inherent value of any social comparison.

Together, these defensive reactions may have been effective in that they may have served to undermine the self-deflation induced by the threatening target in this study. That may be why 
the self-deflation obtained for fourth-year students was weaker than the self-enhancement obtained for first-year students.

\section{Study 3. Attainability: An Outstanding Student Has Different Consequences for Students Holding Stable and Malleable Theories of Intelligence}

We predicted that superstars would induce inspiration and self-enhancement when their accomplishments seemed attainable but demoralization and self-deflation when their accomplishments seemed unattainable. Study 2 provided partial support for these predictions. It is evident that the perceived attainability of a superstar's success can determine the star's consequences for the self and that a model of attainable success can be inspiring. We found clear evidence that an outstanding graduating student could inspire and enhance the self-views of entering students, for whom comparable success seemed attainable. It also appears that a model of unattainable success can be threatening and can induce motivated reasoning aimed at dispelling the threat (Kunda, 1990; Tesser, 1988). It is less clear whether the end result in such cases will be self-deflation. We found that graduating students, for whom the target's level of success was no longer attainable, were somewhat deflated, as predicted, but not significantly so. It seems possible that the defenses that threatened individuals engage in can sometimes protect the self so effectively that self-views remain unchanged.

In Study 3, we further examined how the perceived attainability of a star's success contributes to the star's impact on others. This time, we varied perceived attainability in a very different manner, relying on ongoing individual differences rather than on external circumstances. People differ in their beliefs about the stability of academic abilities. Some view intelligence as fixed and unalterable, whereas others view it as malleable and increasable (Dweck \& Leggett, 1988). We reasoned that people's beliefs about the stability of academic ability could influence the extent to which the achievements of an academic star would seem attainable to them. Those who view academic ability as stable and fixed should assume that they will be unable to improve or develop their own academic performance and so will never reach the star's level of excellence. These individuals should be discouraged by the star. In contrast, those who view academic ability as malleable and capable of improving over time may believe that they will be able to match the star's achievements in the future, as their own abilities develop. These individuals should be inspired and self-enhanced by the star.

\section{Method}

Participants. Participants were 58 University of Waterloo undergraduates of both genders enrolled in Introductory Psychology who participated for course credit. Participants' gender had no effect on any of the variables and therefore is not discussed further. We excluded fourthyear students because, on the basis of the results of Study 2, we believed that they would feel threatened by the target (again a graduating student) regardless of their theory of intelligence. One participant was removed from the analyses because she had changed her academic major since completing the prescreening questionnaire and consequently read about a target in a nonrelevant major. Altogether, 57 participants were included in the analyses.

Pretesting. At the beginning of the term, participants filled out a lengthy prescreening measure that included a questionnaire assessing their theories of intelligence. Participants rated a set of 20 items on an 11-point scale with endpoints labeled 1 (not at all true) and 11 (very true). Six items expressed a belief that intelligence is malleable (e.g., "People can become more intelligent over the course of their lifetime," "Intelligence is influenced by the environment a person lives in"). Six items expressed a belief that intelligence is fixed (e.g., "Intelligence is genetically pre-determined," "Extra schooling cannot make a person more intelligent"). The remaining 8 items addressed other aspects of academic skills (e.g., "People who excel at mathematics also tend to excel at languages") and were included to prevent participants from guessing the true purpose of the questionnaire.

We randomly selected participants from among those who had completed the theory of intelligence measure and subsequently used their scores on this measure to divide them into a malleable-theory group and a fixed-theory group, on the basis of a median split. We also assessed participants' academic major in this pretesting questionnaire.

Procedure. Two to 10 weeks after completing the pretesting questionnaire, participants were recruited for a study on the effect of journalistic styles on social perception and participated individually in a lab setting. The experimenter was unaware of their theory of intelligence score. Participants were randomly assigned to either the experimental or the control condition. Experimental participants read a bogus newspaper article about an outstanding student. The article was similar to the one used in Study 2: The target was academically gifted, a student leader, and involved in various sports and volunteer activities. To ensure relevance, the article was tailor-made for each participant, so that each student read about a target in his or her own academic program; for example, a computer science major read about a computer science student, and an English major read about an English student. The target was always of the same gender as the participant.

After reading the article, experimental participants rated the target and then themselves on the same success-related traits used in Study 2 and on the same perceived relevance measure. Control participants completed the self-ratings without first reading the article about the target.

\section{Results and Discussion}

Prior theory. The six items on the theory of intelligence scale that reflected fixed theories were reverse-scored and averaged with the six items that reflected malleable theories to form a single malleability of intelligence index (Cronbach's $\alpha=.69$ ). Participants scoring above the median on this measure were considered to have malleable theories of intelligence, whereas those scoring below the median were considered to have fixed theories. This resulted in sample sizes ranging from 11 to 17 in the four cells of the 2 (theory) $\times 2$ (condition) design.

To ensure that experimental and control participants within each theory group did not differ in their prior theories of intelligence, we conducted a $2 \times 2$ ANOVA on the malleability index. There were no effects for condition or for the interaction (both $p$ s $>.20)$. Of course, malleable-theory participants $(M=8.96)$ had substantially higher malleability scores than did fixed-theory participants $(M=6.98), F(1,54)=151.16, p<.001$.

Ratings of target. Success-related items were averaged into a single index of the target's success after first reversing the negative items (Cronbach's $\alpha=.85$ ). Experimental participants holding fixed and malleable theories did not differ in their ratings of the target ( $M \mathrm{~s}=9.81$ and 9.98 , respectively; $F<1$ ), with both groups rating the target as highly successful.

Self-ratings. Self-ratings were averaged into an index of 
success as target ratings had been (Cronbach's $\alpha=.92$ ). As expected, the outstanding target exerted a different impact on fixed- and malleable-theory participants, as indicated by the significant Condition $\times$ Theory interaction, $F(1,54)=4.82, p$ $<.05$. As can be seen in Table 3, malleable-theory participants, who were expected to view the target's accomplishments as attainable, were enhanced by the target: Malleable-theory participants exposed to the outstanding student rated themselves more positively than did malleable-theory controls, $F(1,54)=$ $5.41, p=.02$. In contrast, fixed-theory participants, who were expected to view the target's achievements as unattainable, were, if anything, diminished by the target. Fixed-theory participants exposed to the target rated themselves less positively than did fixed-theory controls, although this difference was not significant $(F<1)$.

It is possible that fixed-theory participants failed to show stronger self-deflation in response to the target because they did not view intelligence as entirely fixed. The mean score of the fixed-theory participants on the malleability of intelligence measure was 6.98, above the midpoint of the 11-point scale. Thus, although these participants believed intelligence to be less alterable than did malleable-theory participants, they nevertheless viewed intelligence as at least somewhat alterable. That may be why the target's impact on them was not more severely negative. In addition, fixed-theory participants may have protected themselves from the negative impact of the upward social comparison through motivated reasoning.

Relevance ratings. As in Study 2, participants who were expected to view the target's achievements as less attainable (i.e., the fixed-theory participants) rated the target as somewhat less relevant to them $(M=7.21)$ than did participants who were expected to view the target's achievements as attainable (i.e., the malleable-theory participants; $M=8.06$ ). This difference, however, was not significant $(F<1)$.

For malleable-theory participants, relevance ratings were highly correlated with self-ratings $(r=.63, p<.01)$. Although a correlation cannot point conclusively to causation, the finding that malleable-theory participants who viewed the target as more relevant rated themselves more highly is consistent with the findings of Study 1 that superstars exert greater impact on selfviews the greater their perceived relevance. For fixed-theory participants, the correlation between relevance ratings and selfratings was weaker and nonsignificant $(r=.22, p>.25)$. Recall that the star exerted no significant impact on the self-ratings of these participants. It is therefore not surprising that the star's relevance was not associated with self-ratings for them.

Table 3

Mean Self-Evaluations of Students Holding Malleable and Fixed Theories of Intelligence Who Were and Who Were Not Exposed to an Outstanding Student

\begin{tabular}{ccc}
\hline & \multicolumn{2}{c}{ Target type } \\
\cline { 2 - 3 } Theory of intelligence & No target & Superstar \\
\hline Malleable & 7.61 & 8.66 \\
Fixed & 7.82 & 7.52 \\
\hline
\end{tabular}

Note. Higher numbers indicate more positive self-evaluations.
Explanations. Participants also explained their responses to the relevance question. Two judges unaware of participants' condition and of the experimental hypotheses coded the explanations of experimental participants. As in Studies 1 and 2, responses were coded for inspiration due to the target on the basis of the same criteria used in those studies. Agreement between the two was 80\%; discrepancies were resolved through discussion.

We expected greater inspiration for malleable-theory participants than for fixed-theory participants. However, mentions of inspiration were low for both groups, $25 \%$ and $28 \%$ respectively, and these proportions did not differ significantly from each other. Mentions of inspiration by malleable-theory participants in this study were substantially lower than by participants exposed to relevant models of attainable success in Study 1 (in which $45 \%$ of participants exposed to a star excelling at their own intended profession were inspired) and in Study 2 (in which $82 \%$ of first-year accounting students were inspired by the stellar graduate of their program). Perhaps this was the case because, in this study, the target matched participants on their college majors rather than on their intended professions. Some majors, such as accounting or engineering, do reflect a clear choice of profession, but many others, such as English or psychology, do not. Therefore, even participants who were positively influenced by the star may have been less likely to view the star as a template embodying all that they were striving for.

We also coded responses for mentions of similarity to the target on dimensions other than major or future occupation, as we had in Study 2. Agreement between the coders was $94 \%$ on this measure. Results provided a conceptual replication of the findings of Study 2. Participants likely to view the target's success as attainable, that is, the malleable-theory participants (37\%), were more likely to mention that they were similar to the target than were participants likely to view the target's success as unattainable, that is, the fixed-theory participants $(7 \% ; z=2.03, p<$ $.05)$. Once again, this finding may reflect motivated reasoning on the part of both groups: Malleable theory participants, for whom comparisons to the target could be self-enhancing, may have exaggerated their similarity to the target, whereas fixedtheory participants, for whom comparisons to the target could be self-deflating, may have played down their similarity to the target.

In sum, this study provided convergent evidence for the finding from Study 2 that the perceived attainability of a relevant star's success can determine the star's impact. The star led to self-enhancement among malleable-theory participants, who likely viewed the star's success as attainable, but not among fixed-theory participants, who likely viewed the star's success as unattainable. Fixed-theory participants showed a nonsignificant tendency in the opposite direction and were less likely to describe themselves as similar to the star. Thus, as in Study 2, we obtained strong evidence that a model of attainable success can have positive consequences for the self and weaker evidence that a model of unattainable success can have negative consequences for the self.

\section{General Discussion}

Superstars can sometimes be inspiring and self-enhancing, sometimes self-deflating, and sometimes have no consequences 
at all for the self. Whether superstars exert any impact on others depends on their perceived relevance. When they do, the direction of that impact depends on the believed attainability of their success: Models of attainable success can be inspiring and selfenhancing, whereas models of unattainable success can be threatening and deflating.

We found strong and consistent evidence that relevant superstars can exert a positive impact when their success seems attainable. Future teachers and accountants were inspired and selfenhanced by an outstanding member of their intended profession (Study 1), first-year accounting students were inspired and selfenhanced by an outstanding graduating accounting student (Study 2), and students who viewed intelligence as malleable and increasable were self-enhanced by a graduating student who had excelled at their own major (Study 3). In all these cases, the star's success seemed attainable in that it was based on excellence at tasks that participants themselves had not yet had the opportunity to tackle. Participants could therefore entertain the belief that their own futures would be as bright as the star's.

Perhaps the most important contribution of these studies is the demonstration that role models who excel at one's own domain of interest can be inspiring. Earlier theorists noted that outstanding individuals can have positive consequences for others' self-views through a process of reflection, that is, through basking in the reflected glory of close others (Brewer \& Weber, 1994; Cialdini et al., 1976; Tesser \& Campbell, 1983; Tesser, 1988). We view inspiration as a different kind of positive reaction to a superstar. Consider, for example, the thoughts and feelings going through the minds of different U.S. viewers as they watch an American athlete receive a gold medal at the Olympics. Some budding athletes may be envisioning themselves standing on that same podium 4 years down the road and resolve to double their efforts to attain this goal. These people are inspired. Others, who harbor no athletic aspirations, may simply feel proud to be American. These people are basking in the reflected glory of a fellow American.

Reflection and inspiration arise under different circumstances. Reflection engages one's collective identity, that is, that aspect of the self that is based on membership in a social group, be it one's family or one's nation (Brewer \& Gardner, 1996; Brewer \& Weber, 1994). It arises when a psychologically close other excels at a domain that is irrelevant to the self and so does not challenge cherished aspects of one's personal identity (Tesser, 1988). It can also arise when the domain of excellence is self-relevant, if one is led to focus on one's social rather than on one's personal self (Brewer \& Weber, 1994). Selfenhancement associated with reflection results from an enhanced view of one's entire group, to which the self has been assimilated.

In contrast, to be inspired, one must engage one's personal identity, that is, one's sense of oneself as a unique individual striving to accomplish personal goals and ambitions (Brewer \& Gardner, 1996; Markus \& Kitayama, 1991). Unlike reflection, inspiration is most likely when the other's domain of excellence is self-relevant, because that is when one is most likely to model oneself on the other. To be inspired by another's outstanding accomplishments, one must believe oneself capable of comparable success. Self-enhancernent stemming from inspiration results from strengthened belief in one's own capabilities.
Whereas reflection has played a central role in earlier models of upward social comparison, inspiration has been mostly overlooked. Theories about social comparisons under threats such as cancer have discussed inspiration (Taylor \& Lobel, 1989), but, for the most part, the notion of inspiration has not been incorporated into theories about upward social comparisons in the domain of ability or achievement (for an exception, see Major et al., 1991). That is why earlier theorists have assumed that when one engages in comparison with a superior other who excelled at a relevant domain, the consequences of this comparison for the self are bound to be negative (Brewer \& Weber, 1994; Tesser \& Campbell, 1983; Tesser, 1988). Our studies suggest otherwise. We have found that comparisons to a superstar who excelled at one's own domain of interest can be self-enhancing and inspiring, if the star's achievements seem attainable.

One may question whether we have really demonstrated inspiration as we claim rather than providing yet another example of reflection. After all, in all our studies the superstars who provoked inspiration were members of participants' in-groupthey were of the same gender and major or intended profession. Superior in-group members can provoke reflection if the ingroup is a minority, because minority status highlights one's social rather than personal self (Brewer \& Weber, 1994). Perhaps members of any college major or profession view themselves as minorities, and so our stars exerted their positive impact through reflection rather than inspiration. We have strong reasons to believe that this was not the case. Participants' selfreports clearly illustrate that they were inspired and were focusing on their personal selves, goals, and ambitions. Admittedly, these accounts were given in response to a question about the self-relevance of the star that may have increased the salience of personal selves. Nevertheless, these self-reports suggest, at the very least, that a relevant star's positive impact can survive the activation of personal selves. Moreover, if the stars provoked only reflection, the believed attainability of their success should not have affected their impact; attainability is crucial to one's own likelihood of achieving personal success, and so to inspiration, but is irrelevant to one's ability to bask in another's reflected glory. But attainability did determine the impact of superstars in our studies, suggesting that the self-enhancement resulted from inspiration rather than reflection.

Participants were self-enhanced and inspired by the star only when the star's success seemed attainable. However, we found little evidence for our prediction that participants would be selfdeflated by a star whose success scemed unattainable. Such participants were somewhat self-deflated, as predicted, but not significantly so. We suspect that the self-deflation induced in these participants was relatively weak not because they did not find the unreachable superstars threatening, but because they had managed to defend themselves successfully against this threat. Gilbert, Giesler, and Morris (1995) suggested that people may compare themselves to others automatically but then mentally undo comparisons to irrelevant others. Our threatened participants may have also attempted to mentally undo the comparison, not because it was irrelevant, but because it was threatening. Tesser and his colleagues have shown that people engage in elaborate cognitive work to diffuse such threats (Tesser \& Campbell, 1983; Tesser et al., 1988). We too found evidence 
for this. In Study 2, threatened fourth-year students appeared to try to minimize the magnitude of the star's performance and to reduce the star's relevance. We also uncovered a new strategy: Threatened participants denigrated the meaningfulness of any social comparison, insisting that people can learn nothing about themselves through comparisons to others. Thus, people may alter their theories about the social world so as to dispel the threat of upward comparison (Klein \& Kunda, 1992; Kunda, 1990).

Our findings about how the self-relevance of a star's domain of excellence affects the star's impact on others contradict Tesser's SEM model (Tesser, 1988). We found that domain selfrelevance can increase the likelihood that an outstanding other will have any impact on the self. We suggested that this was because domain self-relevance, like psychological closeness, can increase the correspondence between the self and other and, thereby, increase the likelihood of comparing oneself to the other. In contrast, in the SEM model, whether the outstanding other will affect the self depends only on the others' psychological closeness. Domain self-relevance plays a different role: It determines whether psychologically close superior others will have a positive or a negative impact on self-views. The SEM model assumes that the impact will be positive when the domain is irrelevant to the self but negative when it is relevant. This may be true when the other's success is unattainable. When the domain is relevant, one will compare oneself to the unreachable superior other and feel inferior. However, when the domain is irrelevant, one will not engage in comparison but may, instead, bask in reflected glory. But Tesser's predictions do not hold when the superior other's success seems attainable. We found that a superior other who has achieved attainable success at a self-relevant domain will exert a positive impact on the self, not, as Tesser predicted, a negative impact. Relevance may still determine the nature of the positive impact, though. We would expect inspiration when the domain is relevant but reflection when it is irrelevant. Reflection would only occur, however, if the other is sufficiently psychologically close, as predicted by Tesser (1988). Otherwise, we expect the star to have no impact, as was the case for future teachers and accountants exposed to a stranger who had excelled in a profession other than their intended one.

Note that we view domain relevance as but one of many factors that jointly determine whether one will compare oneself to another (Holyoak \& Thagard, 1995; Thagard \& Kunda, in press ). It may be possible to increase the relevance of seemingly irrelevant superstars by stressing their similarity to the self on other dimensions or by pointing to similarity in the underlying structure and relations of one's life. Structural similarity, that is, similarity based on underlying patterns of relations among elements, can lead people to form analogies among objects that are superficially quite different from each other (Holyoak \& Thagard, 1995). For example, one may draw an analogy between a woman and a squirrel if both are seen receiving food from another (Markman \& Gentner, 1993). If one can compare a woman to a squirrel, surely one should be able to compare a professor to an athlete or a teacher to an accountant. Such comparisons may be facilitated if the star's accomplishments are described in general rather than specific terms. Whereas an Olympic medal may be irrelevant to a professor, achieving the top honor in one's field is undoubtedly a relevant goal. It would be of great theoretical and practical interest to determine whether it is possible to broaden the appeal of outstanding role models in this manner.

Our work has important practical implications for how to maximize the benefits of role models. We found that, consistent with lay intuitions, role models can be inspiring. But an inappropriate role model may fail to have any impact on others. This is the most likely outcome when the role model is a stranger whose domain of excellence seems irrelevant to the target audience. Worse, an inappropriate role model may lead to discouragement and self-deflation rather than the desired inspiration. This is likely to occur when the role model has achieved unattainable success at one's own domain of interest. A star's success can seem unattainable when the star is a peer and so already unreachable or when the star's success is so extreme as to appear beyond most people's grasp. It seems that the ideal role model is a person who is somewhat older and at a more advanced career stage than the target individuals and who has achieved what these individuals hope for - outstanding but not impossible success at an enterprise in which they too wish to excel.

\section{References}

Baron, R. M., \& Kenny, D. A. (1986). The moderator-mediator variable distinction in social psychological research: Conceptual, strategic, and statistical considerations. Journal of Personality and Social Psychology, 51, 1173-1182.

Brewer, M. B., \& Gardner, W. (1996). Who is this "we"? Levels of collective identity and self representations. Journal of Personality and Social Psychology, 71, 83-93.

Brewer, M. B., \& Weber, J. G. (1994). Self-evaluation effects on interpersonal versus intergroup social comparison. Journal of Personality and Social Psychology, 66, 268-275.

Brickman, P., \& Bulman, R. J. (1977). Pleasure and pain in social comparison. In J. M. Suls \& R. L. Miller (Eds.), Social comparison processes: Theoretical and empirical perspectives (pp. 149-186). Washington, DC: Hemisphere.

Brown, J. D., Novick, N. J., Lord, K. A., \& Richards, J. M. (1992). When Gulliver travels: Social context, psychological closeness, and self-appraisals, Journal of Personality and Social Psychology, 62 . $717-727$

Buunk, B. P., Collins, R. L., Taylor, S. E., VanYperen, N. W., \& Dakof, G. A. (1990). The affective consequences of social comparison: Either direction has its ups and downs. Journal of Personality and Social Psychology, 59, 1238-1249.

Cash, T. F., Cash, D. W., \& Butters, J. W. (1983). "Mirror, mirror, on the wall . .?'": Contrast effects and self-evaluations of physical attractiveness. Personality and Social Psychology Bulletin, 9, 35I358.

Cialdini, R. B., Borden, R. J., Thome, A., Walker, M. R., Freeman, S., \& Sloan, L. R. ( 1976). Basking in reflected glory: Three (football) field studies. Journal of Personality and Social Psychology, 34, 366-375.

Collins, R. L. (1996). For better or worse: The impact of upward social comparisons on self-evaluations. Psychological Bulletin, 119, 51-69.

Dweck, C. S., \& Leggett, E. L. (1988). A social-cognitive approach to motivation and personality. Psychological Review, 95, 256-273.

Festinger, L. (1954). A theory of social comparison processes. Human Relations, 7, 117-140.

Forman, M. (Director). (1984). Amadeus [ film]. (Available from Republic Pictures, Los Angeles, California.)

Gastorf, J. W., \& Suls, J. (1978). Performance evaluation via social 
comparison: Performance similarity versus related attribute similarity. Social Psychology, 41, 297-305.

Gilbert, D. T., Giesler, R. B., \& Morris, K. A. (1995). When comparisons arise. Journal of Personality and Social Psychology, 69, 227236.

Goethals, G. R., \& Darley, J. M. (1977). Social comparison theory. In J. M. Suls \& R. L. Miller (Eds.), Social comparison processes: Theoretical and empirical perspectives (pp. 259-278). Washington, DC: Hemisphere.

Holyoak, K. J., \& Thagard, P. ( 1989). Analogical mapping by constraint satisfaction. Cognitive Science, 13, 295-355.

Holyoak, K. J., \& Thagard, P. (1995). Mental leaps: Analogy in creative thought. Cambridge, MA: MIT Press/Bradford Books.

Klein, W. M., \& Kunda, Z. (1992). Motivated person perception: Constructing justifications for desired beliefs. Journal of Experimental Social Psychology, 28, 145-168.

Kunda, Z. (1990). The case for motivated reasoning. Psychological Bulletin, 108, 480-498.

Major, B., Sciacchitano, A., \& Crocker, J. (1993). In-group versus outgroup comparisons and self-esteem. Personality and Social Psychology Bulletin, 19, 711-721.

Major, B., Testa, M., \& Bylsma, W. H. (1991). Responses to upward and downward social comparisons: The impact of esteem-relevance and perceived control. In J. Suls \& T. A. Wills (Eds.), Social comparison: Contemporary theory and research (pp. 237-260). Hillsdale, $\mathrm{NJ}$ : Erlbaum.

Markman, A. B., \& Gentner, D. (1993). Structural alignment during similarity comparisons. Cognitive Psychology, 25, 431-467.

Markus, H., \& Kitayama, S. (1991). Culture and the self: Implications for cognition, emotion, and motivation. Psychological Review, 98, 224-252.

Markus, H., \& Nurius, P. (1986). Possible selves. American Psychologist, 41, 954-969.

Meichenbaum, D. H. (1971), Examination of model characteristics in reducing avoidance behavior. Journal of Personality and Social Psychology, 17, 298-307.

Morse, S., \& Gergen, K. J. (1970). Social comparison, self-consistency, and the concept of self. Journal of Personality and Social Psychology, 16. $148-156$

Pelham, B. W., \& Wachsmuth, J. O. (1995). The waxing and waning of the social self: Assimilation and contrast in social comparison. Journal of Personality and Social Psychology, 69, 825-838.

Pleban, R., \& Tesser, A. (1981). The effects of relevance and quality of another's performance on interpersonal closeness. Social Psychology Quarterly, 44, 278-285.

Salovey, P., \& Rodin, J. (1984). Some antecedents and consequences of social comparison jealousy. Journal of Personality and Social Psychology, 47, 780-792.

Seta, F. (1982). The impact of comparison processes on coactors' task performance. Journal of Personality and Social Psychology, 42, 281 291.

Taylor, S. E., \& Lobel, M. (1989). Social comparison activity under threat: Downward evaluation and upward contacts. Psychological Review, 96, 569-575.

Tesser, A. (1986). Some effects of self-evaluation maintenance on cognition and action. In R. M. Sorrentino \& E. T. Higgins (Eds.), The handbook of motivation and cognition: Foundations of social behavior (pp. 435-464). New York: Guilford Press.

Tesser, A. (1988). Toward a self-evaluation maintenance model of social behavior. In L. Berkowitz (Ed.), Advances in experimental social psychology, (pp. 181-227). New York: Academic Press.

Tesser, A. (1991). Emotion in social comparison and reflection processes. In J. Suls \& T. A. Wills (Eds.), Social comparison: Contemporary theory and research (pp. 115-145). Hillsdale, NJ: Erlbaum.

Tesser, A., \& Campbell, J. (1983). Self-definition and self-evaluation maintenance. In J. Suls \& A. Greenwald (Eds.), Social psychological perspectives on the self (pp. 1-31). Hillsdale, NJ: Erlbaum.

Tesser, A., \& Cornell, D. P. (1991). On the confluence of self processes. Journal of Experimental Social Psychology, 27, 501-526.

Tesser, A., Millar, M., \& Moore, J. (1988). Some affective consequences of social comparison and reflective processes: The pain and pleasure of being close. Journal of Personality and Social Psychology, 54, $49-61$.

Tesser, A., \& Paulhus, D. (1983). Self-definition of self: Private and public self-evaluation strategies. Journal of Personality and Social Psychology, 44, 672-682.

Testa, M., \& Major, B. (1990). The impact of social comparison after failure: The moderating effects of perceived control. Basic and Applied Social Psychology, 11, 205-218.

Thagard, P., \& Kunda, Z. (in press). Making sense of people: Coherence mechanisms. In S. Read (Ed.), Connectionist and PDP models of social reasoning and social behavior. Hillsdale, $\mathrm{NJ}$ : Erlbaum.

Wood, J. V. (1989). Theory and research concerning social comparisons of personal attributes. Psychological Bulletin, 106, 231-248.

Wood, J. V., \& VanderZee, K. (in press). Social comparisons among cancer patients: Under what conditions are comparisons upward and downward? In B. P. Buunk \& F. X. Gibbons (Eds.), Social comparison, health, and coping. Hillsdale, NJ: Erlbaum.

Received November 13, 1996

Revision received February 28, 1997 Accepted March 3, 1997 